\title{
Produção de ácido lático em meio à base de efluentes da indústria de alimentos por cultura láctea mista imobilizada
}

\section{Production of lactic acid in a medium based on food industry effluents using an immobilized mixed dairy culture}

Carolina Lilibeth Carvalho de Pinho ${ }^{1}$, Caroline Eliza Sgarbosa de Oliveira ${ }^{1}$, Jamille Coelho Coimbra ${ }^{2}$, Weskley da Silva Cotrim ${ }^{1 *}$ (1)

${ }^{1}$ Universidade Federal de Mato Grosso (UFMT), Instituto de Ciências Exatas e da Terra, Laboratório de Engenharia de Processos Industriais, Campus Universitário do Araguaia, Barra do Garças/MT - Brasil

${ }^{2}$ Universidade Federal de Viçosa (UFV), Departamento de Tecnologia de Alimentos, Viçosa/MG - Brasil

${ }^{*}$ Corresponding Author: Weskley da Silva Cotrim, Universidade Federal de Mato Grosso (UFMT), Instituto de Ciências Exatas e da Terra, Laboratório de Engenharia de Processos Industriais, Campus Universitário do Araguaia, Av. Valdon Varjão, 6390, CEP: 78600-000, Barra do Garças/MT - Brasil, e-mail: weskleycotrim@ufmt.br

Cite as: Pinho, C. L. C., Oliveira, C. E. S., Coimbra, J. C., \& Cotrim, W. S (2019). Production of lactic acid in a medium based on food industry effluents using an immobilized mixed dairy culture. Brazilian Journal of Food Technology, 22, e2018100. https://doi.org/10.1590/1981-6723.10018

\begin{abstract}
Resumo
O ácido polilático (PLA), o mais conhecido bioplástico com potencial para ser o substituto dos polímeros derivados do petróleo, é produzido pela polimerização do ácido lático. A aplicação do ácido lático para a produção de ácido polilático tem levado a um aumento substancial no seu consumo. Entretanto, o custo da matéria-prima representa um grande obstáculo na produção econômica de ácido lático para essa finalidade. Assim, vários materiais têm sido considerados como substratos alternativos, incluindo subprodutos de indústrias agrícolas, indústrias de alimentos e biomassas naturais. O presente trabalho avaliou o uso de resíduos da indústria de alimentos como suplemento nutricional do soro de leite para produção de ácido lático por cultura mista imobilizada de bactérias láticas (Lactobacillus acidophilus LA-5, Bifidobacterium BB-12 e Streptococcus thermophilus). Foram testadas três condições de $\mathrm{pH}(6,0 ; 6,5$ e 7,0$)$ e três condições de temperatura $\left(30^{\circ} \mathrm{C}, 35^{\circ} \mathrm{C}\right.$ e $\left.40^{\circ} \mathrm{C}\right)$ de fermentação. Também foram testados três níveis de suplementação do soro de leite com cada um dos resíduos: água de maceração de milho - AMM $(0 \%$, $5 \%$ e $10 \%)$; vinhaça $(0 \%$, $5 \%$ e $10 \%$ ) e extrato de levedura ( $0 \%$, 3\% e $6 \%)$. Ao final da fermentação, observou-se que os tratamentos com temperatura de $40^{\circ} \mathrm{C} \mathrm{e} \mathrm{o} \mathrm{pH} \mathrm{inicial} \mathrm{de} 7,0$ apresentaram teor de ácido lático $10 \%$ superior aos demais. Todos os resíduos foram efetivos em aumentar a produção de ácido lático quando suplementados no soro de leite. $O$ extrato de levedura apresentou a maior concentração de ácido lático, com 0,0307 mol..-1-1, resultado $20 \%$ superior ao da água de maceração de milho e vinhaça.
\end{abstract}

Palavras-chave: Extrato; Levedura; Vinhaça; Maceração; Milho; Fermentação.

\begin{abstract}
Polylactic acid (PLA), the best-known bioplastic with the potential to substitute polymers derived from petroleum, is produced by lactic acid polymerization. The application of lactic acid in the production of polylactic acid has led to a substantial increase in the world consumption of this acid. However, the cost of the raw material represents a
\end{abstract}


major obstacle in the economic production of lactic acid for this purpose. Thus, many materials have been considered as alternative substrates, including by-products from agricultural industries, food industries and natural biomasses. The present work evaluated the use of residues from the food industry as a nutritional supplement for the whey used in the production of lactic acid by an immobilized mixed culture of lactic acid bacteria (Lactobacillus acidophilus LA-5, Bifidobacterium BB-12 and Streptococcus thermophilus). Three pH conditions (6.0, 6.5 and 7.0) and three fermentation temperatures $\left(30^{\circ} \mathrm{C}, 35^{\circ} \mathrm{C}\right.$ and $\left.40^{\circ} \mathrm{C}\right)$ were tested. Three levels of whey supplementation were also tested with each of the residues: corn maceration water - AMM (0\%, $5 \%$ and $10 \%)$; vinasse $(0 \%, 5 \%$ and $10 \%)$ and yeast extract $(0 \%, 3 \%$ and $6 \%)$. At the end of the fermentations, it could be seen that the treatments with a temperature of $40{ }^{\circ} \mathrm{C}$ and an initial $\mathrm{pH}$ of 7.0 presented a lactic acid content $10 \%$ higher than the other treatments. All the residues were effective in increasing the lactic acid production when used to supplement the whey. The yeast extract presented the highest concentration of lactic acid, with 0.0307 mol. $\mathrm{L}^{-1}$, a result $20 \%$ higher than that obtained with corn maceration water and vinasse.

Keywords: Extract; Yeast; Vinasse; Maceration; Corn; Fermentation.

\section{Introdução}

O ácido lático possui ampla aplicação como matéria-prima para várias indústrias, tais como a indústria de alimentos, indústria farmacêutica, de couro e indústrias têxteis. A aplicação do ácido lático para a produção de ácido polilático (PLA), o mais conhecido bioplástico que pode ser o substituto dos polímeros derivados do petróleo, tem levado a um aumento substancial no consumo mundial desse ácido (Tosungnoen et al., 2014; Vijayakumar et al., 2008). No entanto, o preço do ácido lático é ainda elevado para a sua utilização econômica na produção de PLA. Desta forma, diversos pesquisadores têm se dedicado ao desenvolvimento de abordagens efetivas para a sua produção, buscando substratos de baixo custo, micro-organismos eficientes e a otimização do processo de fermentação (Ding \& Tan, 2006; Tosungnoen et al., 2014; Wee et al., 2006).

O custo da matéria-prima é um dos principais fatores que interferem na produção econômica de ácido lático. Assim, vários materiais têm sido considerados como substratos alternativos, incluindo subprodutos de indústrias agrícolas, indústrias de alimentos e biomassas naturais não utilizadas (Abdel-Rahman et al., 2013; Bai et al., 2016; Bonk, et al., 2017). Resíduos agroindustriais vêm sendo utilizados, não só como fonte de carbono, mas também como fonte orgânica de nitrogênio, o qual é utilizado nos processos anabólicos e catabólicos, e está disponível na forma de aminoácidos, peptídeos e componentes inorgânicos (Martinez et al., 2013)

Para sua utilização como substrato, o resíduo deve atender aos requisitos nutricionais do micro-organismo empregado no processo. Nesse sentido, o soro de leite se apresenta como uma boa alternativa, uma vez que apresenta uma composição rica em lactose, proteínas, gorduras, vitaminas e sais minerais, atendendo à maioria dos requisitos nutricionais dos micro-organismos fermentadores, especialmente as bactérias do ácido lático (BAL), o grupo mais largamente utilizado na produção do ácido lático (Abdel-Rahman et al., 2013). Segundo Hofvendahl \& Hahn-Hagerdal (2000), um grande número de diferentes substratos tem sido utilizado na produção de ácido lático por fermentação de bactérias láticas, uma vez que essas bactérias não produzem quantidades suficientes de enzimas proteolíticas, se faz necessária a suplementação do meio com uma fonte de aminoácidos e vitaminas lipossolúveis (Panesar et al., 2007), os quais podem ser fornecidos por outros resíduos, nutricionalmente ricos, da indústria de alimentos, tais como bagaço, melaço e vinhaça de cana-deaçúcar, manipueira, além da água de maceração de milho (AMM), do autolisado de levedura e de outros resíduos de alimentos (Bernardo et al., 2016; Zheng et al., 2017).

Nesse sentido, o presente trabalho visou ao estudo do uso de resíduos da indústria de alimentos como suplemento nutricional em meio à base de soro de leite para produção de ácido lático por cultura mista imobilizada de bactérias láticas (Lactobacillus acidophilus LA-5, Bifidobacterium BB-12 e Streptococcus thermophilus). 


\section{Material e métodos}

Foi utilizada uma cultura mista liofilizada da marca Bio-Rich ${ }^{\circledR}$ (Lactobacillus acidophilus LA-5, Bifidobacterium BB-12 e Streptococcus thermophilus). A cultura lática desidratada (40 mg) foi reativada em $100 \mathrm{~mL}$ de leite UHT e incubada por uma hora a $45^{\circ} \mathrm{C}$, em incubadora com agitação orbital, até concentração final estimada de $1 \times 10^{5} \mathrm{UFC} / \mathrm{mL}$, sendo essa a pré-cultura utilizada no processo de imobilização celular.

Todos os meios fermentativos utilizados neste estudo foram elaborados pela suplementação do soro de leite por extrato de levedura, água de maceração de milho ou vinhaça. O soro de leite foi obtido a partir de leite pasteurizado. Para cada $1.000 \mathrm{~mL}$ de leite, adicionou-se $1 \mathrm{~mL}$ da enzima quimosina, conforme recomendação do fabricante (HA-LA ${ }^{\circledR}$ - Chr. Hansen Holding A/S), e $0,5 \mathrm{~mL}$ de solução de cloreto de cálcio $40 \%$. Após esse procedimento, o leite foi incubado a $36{ }^{\circ} \mathrm{C}$ por duas horas. Decorrido esse tempo, o soro foi separado do coágulo por filtração simples e, na sequência, aquecido em banho-maria a $95{ }^{\circ} \mathrm{C}$, durante 30 minutos, e filtrado novamente para remoção do material precipitado.

O extrato de levedura e a vinhaça foram produzidos por fermentação alcoólica de solução de açúcar mascavo $15 \%(\mathrm{~m} / \mathrm{m})$ por cultura desidratada de Saccharomyces cerevisiae, incubada por $48 \mathrm{~h}$ a $30^{\circ} \mathrm{C}$. Após fermentação, o material foi destilado para remoção do álcool e obtenção da vinhaça. Parte da vinhaça foi centrifugada a $3.500 \mathrm{rpm}$ por $15 \mathrm{~min}$, sendo o sobrenadante descartado e o precipitado (extrato de levedura) coletado e armazenado.

Para o preparo água de maceração de milho, $300 \mathrm{~g}$ milho semiduro foram adicionados a um erlenmeyer contendo a solução de maceração constituída por $950 \mathrm{~mL}$ de água destilada, $5 \mathrm{~mL}$ de ácido lático e 2,5 gramas de metabissulfito de sódio, para liberação do $\mathrm{SO}_{2}$ (Lopes-Filho et al., 2006). Os grãos foram então macerados em incubadora Shaker por 48 horas à temperatura de $50{ }^{\circ} \mathrm{C}$ sob agitação. Após esse período, a água de maceração foi filtrada e aquecida a $90{ }^{\circ} \mathrm{C}$ por três horas.

A etapa de imobilização foi realizada por meio do aprisionamento de células em gel de alginato de cálcio, conforme descrito por Mirdamadi et al. (2008), com modificações. Prepararam-se $40 \mathrm{~mL}$ de solução de alginato de sódio $2,5 \%$, à qual foram adicionados $30 \mathrm{~mL}$ da pré-cultura microbiana. Essa mistura foi transferida para uma bureta e gotejada em uma solução de cloreto de cálcio 0,2 M. Cada gota, ao entrar em contato com o cloreto de cálcio, forma uma esfera, contendo dentro dela as células imobilizadas. As esferas formadas, contendo as células imobilizadas, foram mantidas em solução de cloreto de cálcio a $4{ }^{\circ} \mathrm{C}$ durante 12 horas, para cura das esferas. Após o período de cura, as esferas foram separadas por filtração e lavadas duas vezes com água destilada, para remoção do excesso de íons de cálcio e células não aprisionadas, sendo assim utilizadas nos ensaios fermentativos.

$\mathrm{O}$ estudo foi realizado em dois experimentos consecutivos. No primeiro, foi avaliado o efeito da temperatura $\left(30^{\circ} \mathrm{C}, 35^{\circ} \mathrm{C}\right.$ e $\left.40^{\circ} \mathrm{C}\right)$ e do $\mathrm{pH}$ inicial $(6,0 ; 6,5$ e 7,0$)$ da fermentação sobre a produção de ácido lático. No segundo experimento, avaliou-se a suplementação do soro de leite com três diferentes resíduos da indústria de alimentos (extrato de levedura, vinhaça e água de maceração de milho).

Na primeira etapa, para cada $\mathrm{pH}$ inicial, foram realizados ensaios em triplicata pela adição de $300 \mathrm{~mL}$ de soro de leite em frascos erlenmeyers de $500 \mathrm{~mL}$, os quais tiveram os $\mathrm{pH}$ ajustados para cada caso. Um frasco de cada $\mathrm{pH}$ inicial foi submetido à fermentação em cada uma das temperaturas em estudo. Todos os frascos foram mantidos nas suas respectivas temperaturas durante seis horas, em estufa BOD. Nos tempos $0 \mathrm{~h}, 0,5 \mathrm{~h}$, $1 \mathrm{~h}, 2 \mathrm{~h}, 3 \mathrm{~h}, 4 \mathrm{~h}, 5 \mathrm{~h}$ e $6 \mathrm{~h}$, uma alíquota foi retirada de cada frasco, totalizando $30 \mathrm{~mL}$, para realização das análises físico-químicas.

Na segunda etapa, foram avaliadas três fontes de nitrogênio, sendo estas o extrato de levedura, a água de maceração de milho e a vinhaça. Um tratamento controle (não suplementado) foi realizado para comparação com aqueles suplementados. Quando utilizada a suplementação, realizaram-se duas fermentações para cada fonte de nitrogênio, variando a concentração adicionada ao soro de leite. Com o extrato de levedura, o meio foi composto de $300 \mathrm{~mL}$ de soro de leite e a adição de $3 \%$ e $6 \%$ de extrato. Na fermentação utilizando a 
AMM como fonte de nitrogênio, a composição do meio foi de $300 \mathrm{~mL}$ de soro de leite e $5 \%$ e $10 \%$ de água de maceração. E, por fim, a fermentação utilizando a vinhaça foi realizada utilizando $300 \mathrm{~mL}$ de soro e $5 \%$ e $10 \%$ de vinhaça. Todos os ensaios foram inoculados com $16 \mathrm{~g}$ de esferas de alginato de cálcio e submetidos às mesmas condições de fermentação, sendo estas a temperatura de $40^{\circ} \mathrm{C}$ e o pH inicial 7,0. Nos tempos $0 \mathrm{~h}$, $0,5 \mathrm{~h}, 1 \mathrm{~h}, 2 \mathrm{~h}, 3 \mathrm{~h}, 4 \mathrm{~h}, 5 \mathrm{~h} \mathrm{e} 6 \mathrm{~h}$, uma alíquota foi retirada de cada frasco, totalizando $30 \mathrm{~mL}$, para realização das análises físico-químicas.

A determinação do teor de ácido lático durante a fermentação foi realizada como descrita por Zenebon et al. (2008). O pH foi determinado por medida direta em amostra mediante inserção do eletrododo pHmetro digital diretamente no frasco de fermentação.

$\mathrm{Na}$ condução das duas etapas do experimento, foi adotado delineamento inteiramente casualizado (DIC), com três repetições. Não foram avaliados efeitos do tempo no processo. Exclusivamente para os fatores temperatura e $\mathrm{pH}$ (primeira etapa), foi adotado arranjo fatorial $3^{2}$, sendo a temperatura (TPR) e o pH inicial $(\mathrm{PH})$, os fatores do delineamento. Os níveis de temperatura foram $30{ }^{\circ} \mathrm{C}, 35^{\circ} \mathrm{C}$ e $40{ }^{\circ} \mathrm{C}$. Os níveis de $\mathrm{pH}$ inicial foram 6,0, 6,5 e 7,0. Os dados foram analisados no software R 3.3.2 (R Core Team, 2016), por meio de análise de variância (ANOVA) e teste de comparações múltiplas (TUKEY), adotando o nível de 5\% de probabilidade.

\section{Resultados e discussão}

\subsection{Influência da temperatura e do pH inicial na produção de ácido lático utilizando células imobilizadas}

A Figura 1 apresenta os resultados para a produção de ácido lático em diferentes condições iniciais de temperatura e pH, após $6 \mathrm{~h}$ de fermentação. Não foram observadas interações significativas entre os tratamentos $(p>0,05)$. A maior concentração de ácido lático foi obtida com a fermentação iniciada com o maior valor de $\mathrm{pH}$ inicial $(7,0)$, decrescendo à medida que o $\mathrm{pH}$ inicial também era reduzido $(p<0,05)$. Quando avaliado o efeito da temperatura, observou-se que a fermentação conduzida a $40{ }^{\circ} \mathrm{C}$ apresentou resultados superiores às demais $(p<0,05)$.

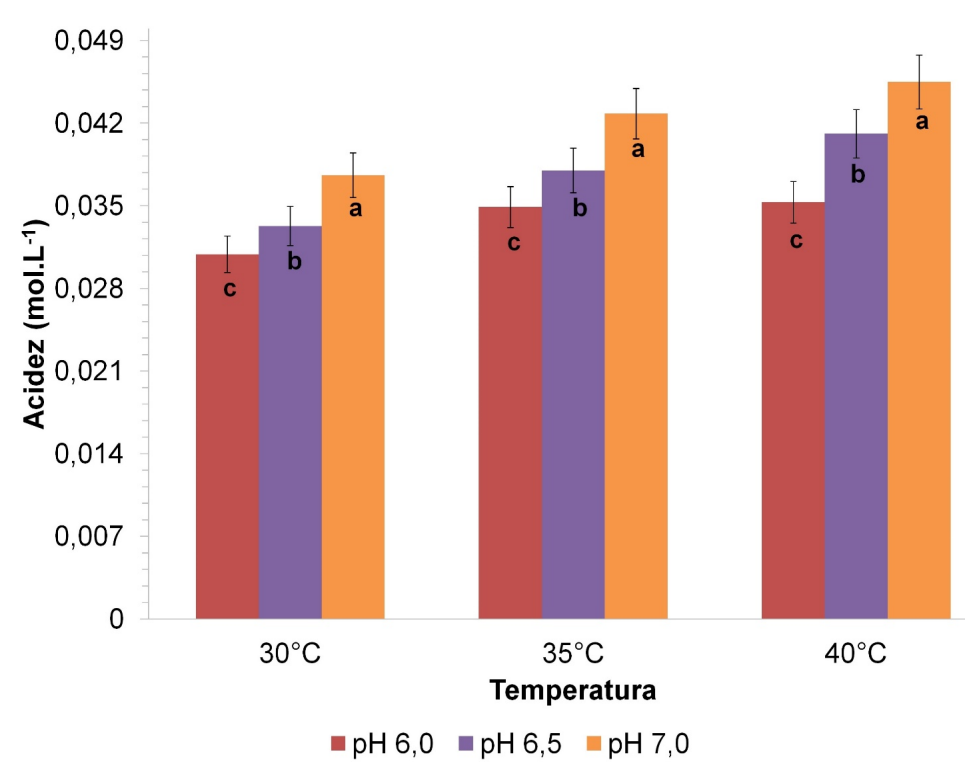

Figura 1. Teor de ácido lático produzido após $6 \mathrm{~h}$ de fermentação por cultura mista de bactérias láticas (Lactobacillus acidophilus LA-5, Bifidobacterium BB-12 e Streptococcus thermophilus) imobilizadas em esferas de alginato de cálcio, em soro de leite. Médias seguidas por letras iguais, na mesma temperatura, não diferem significativamente pelo teste de Tukey $(p>0,05)$. 
$\mathrm{O}$ pH do meio de fermentação influencia diretamente na produção de ácido lático, pois os microorganismos dependem do $\mathrm{pH}$ intracelular e extracelular, e este afeta a atividade catalítica das enzimas e o seu metabolismo (Mozzi et al., 2015). Segundo Hofvendahl \& Hahn-Hagerdal (1997), ácidos fracos inibem o crescimento bacteriano, porque, com a queda do $\mathrm{pH}$ externo, o ácido é protonado, se difunde para a célula e dissocia-se devido ao $\mathrm{pH}$ superior intracelular. A célula então tem de usar ATP para bombear os prótons para seu exterior e, desta forma, a energia é totalmente utilizada para a manutenção da homeostase do $\mathrm{pH}$, ocorrendo a parada do crescimento e, consequentemente, a morte das bactérias. Além disso, ocorre a autólise das células em altas concentrações de ácido lático e a sua produção praticamente cessa quando o meio de fermentação atinge valores de $\mathrm{pH}$ próximos a 4,0. Isso explica por que maiores concentrações de ácido lático foram obtidas em pH inicial equivalente a 7,0, uma vez que, nesta condição, as bactérias láticas possuem condições mais favoráveis para adaptação e multiplicação em comparação ao pH inicial 6,0 e 6,5, levando a uma maior produção de ácido lático.

\subsection{Avaliação das fontes alternativas de nitrogênio}

Foram avaliadas três fontes de nitrogênio (água de maceração de milho, a vinhaça e o extrato de levedura) utilizadas para suplementação do meio de cultura (soro de leite) para fermentação com células imobilizadas. Como a produção de ácido lático foi superior na temperatura de $40{ }^{\circ} \mathrm{C}$ e $\mathrm{pH}$ inicial 7,0 , estas foram as condições de trabalho adotadas neste experimento.

A Figura 2 apresenta o perfil de produção de ácido lático, em seis horas de fermentação, com a utilização da água de maceração de milho (AMM) como suplemento nutricional para a cultura mista de bactérias láticas. Foram testadas as concentrações de $0 \%, 5 \%$ e $10 \%$ de suplementação do soro de leite com a água de maceração de milho.

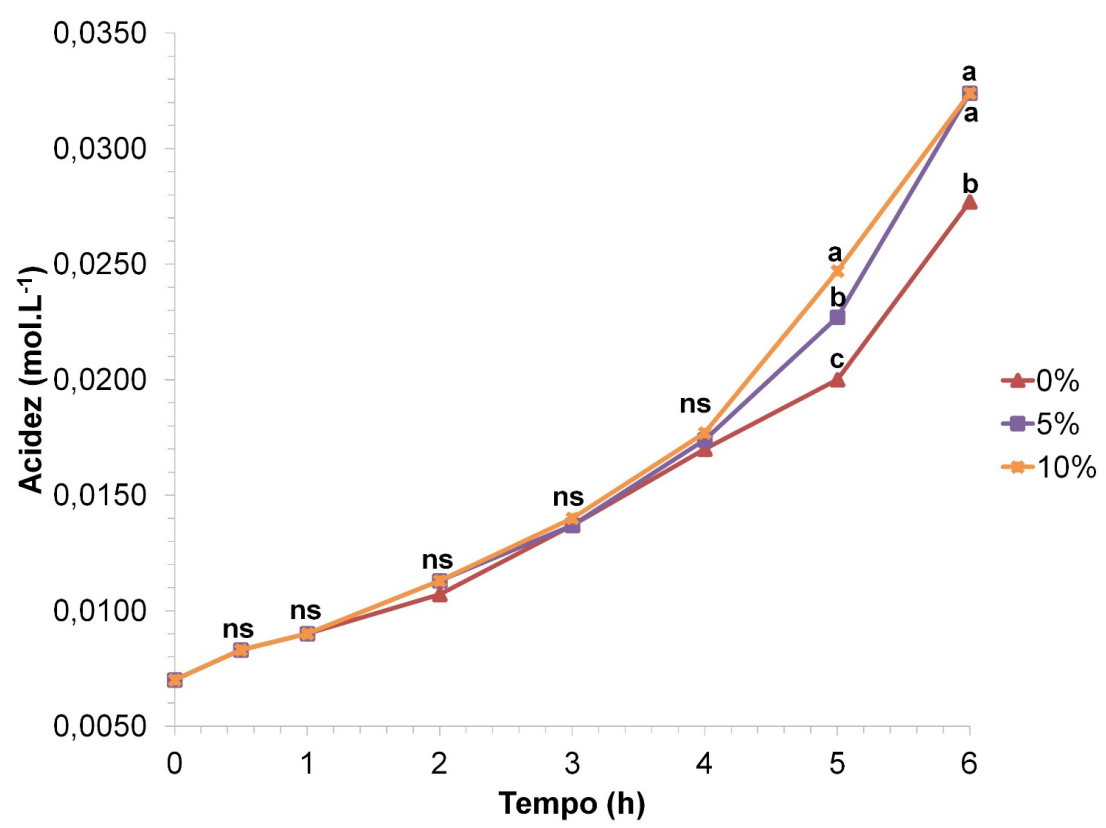

Figura 2. Produção de ácido lático por cultura mista de bactérias láticas (Lactobacillus acidophilus LA-5, Bifidobacterium BB-12 e Streptococcus thermophilus), imobilizadas em esferas de alginato de cálcio, em soro de leite suplementado com água de maceração de milho - AMM (pH inicial 7,0 e temperatura $40{ }^{\circ} \mathrm{C}$ ). ns: Não significativo. Médias seguidas por letras iguais, no mesmo tempo, não diferem significativamente pelo teste de Tukey $(p>0,05)$.

Observa-se que, até o tempo de $4 \mathrm{~h}$, a adição da AMM não apresentou vantagem para aumento da produção de ácido lático, não sendo observada diferença significativa entre os tratamentos ( $p>0,05)$. Entretanto, após $5 \mathrm{~h}$ de fermentação, a suplementação começa a apresentar efeito positivo na produção de ácido lático 
$(p<0,05)$, quando esse tratamento é comparado ao tratamento controle $(0 \%)$. Ao final da fermentação, ficou evidente a vantagem da suplementação do soro de leite com água de maceração de milho, observando-se um incremento de cerca de $17 \%$ na produção de ácido lático. Entretanto, não foi observada diferença significativa $(p>0,05)$ na produção de ácido lático entre os tratamentos 5\% e 10\% de AMM.

No trabalho publicado por Lima et al. (2009), investigou-se a produção de ácido lático por Lactobacillus $s p$., utilizando melaço de cana-de-açúcar enriquecido com água de maceração de milho e autolisado de levedura. As maiores concentrações de ácido lático foram encontradas nos meios em que foram adicionados $15 \mathrm{~g} / \mathrm{L}$ de $\mathrm{AMM}$ e $5 \mathrm{~g} / \mathrm{L}$ de autolisado de levedura $(41,4 \mathrm{~g} / \mathrm{L})$. O experimento em que não foi adicionado a AMM como suplemento apresentou a menor produção de ácido lático $(12,1 \mathrm{~g} / \mathrm{L})$.

$\mathrm{Na}$ fermentação utilizando vinhaça como fonte de nitrogênio (Figura 3), a vantagem na suplementação é evidenciada a partir de $2 \mathrm{~h}$ de fermentação, em que os tratamentos com $5 \%$ e $10 \%$ de suplementação apresentaram maiores concentrações de ácido lático, quando comparadas ao tratamento controle $(0 \%)$ $(p<0,05)$. Ao final do experimento, não se verificou vantagem do tratamento de $10 \%$ frente àquele com $5 \%$ de suplementação do soro de leite por vinhaça. Entretanto, fica evidente a vantagem da suplementação, uma vez que os tratamentos que receberam a vinhaça produziram até $48 \%$ mais ácido lático $(p<0,05)$, quando comparados ao tratamento controle $(0 \%)$.

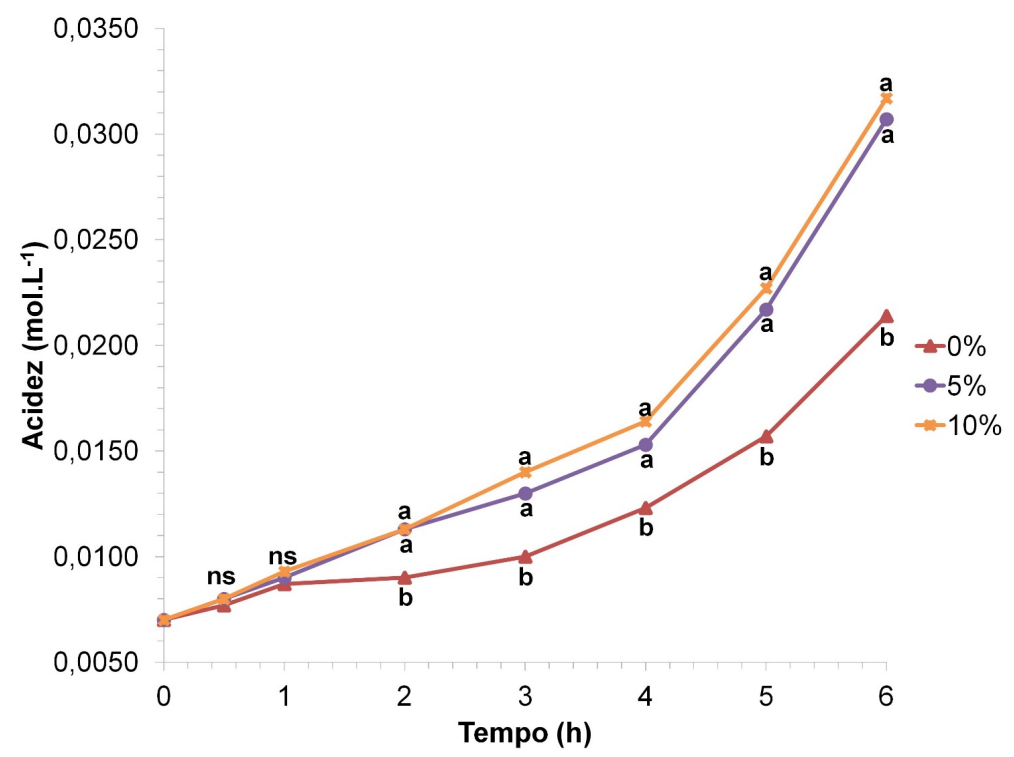

Figura 3. Produção de ácido lático por cultura mista de bactérias láticas (Lactobacillus acidophilus LA-5, Bifidobacterium BB-12 e Streptococcus thermophilus), imobilizadas em esferas de alginato de cálcio, em soro de leite suplementado com vinhaça ( $\mathrm{pH}$ inicial 7,0 e temperatura $40^{\circ} \mathrm{C}$ ). ns: Não significativo. Médias seguidas por letras iguais, no mesmo tempo, não diferem significativamente pelo teste de Tukey $(p>0,05)$.

A matéria nitrogenada representa cerca de $28 \%$ de toda a matéria seca presente na vinhaça, se apresentando na forma de proteínas e aminoácidos livres, dentre outros componentes (Dowd et al., 1994; Zali et al., 2017). A vinhaça possui quantidades livres apreciáveis de asparagina $\left(42,6 \mathrm{mg} \mathrm{L}^{-1}\right)$, glicina $\left(1050,9 \mathrm{mg} \mathrm{L}^{-1}\right)$, leucina (3148,1 $\left.\mathrm{mg} \mathrm{L}^{-1}\right)$ e alanina $\left(134,9 \mathrm{mg} \mathrm{L}^{-1}\right)$, todas estas consideradas aminoácidos essenciais para o crescimento de Lactobacillus acidophilus (Silva et al., 2017; Soska, 1966). Além disso, também são observadas quantidades significativas de potássio e fósforo, minerais também necessários ao metabolismo microbiano, o que explica o efeito positivo da suplementação do soro de leite com esse resíduo (Zali et al., 2017).

A Figura 4 apresenta o efeito positivo na produção de ácido lático ao se utilizar soro de leite suplementado com extrato de levedura como meio de cultivo para cultura mista imobilizada em esferas de alginato de cálcio. 


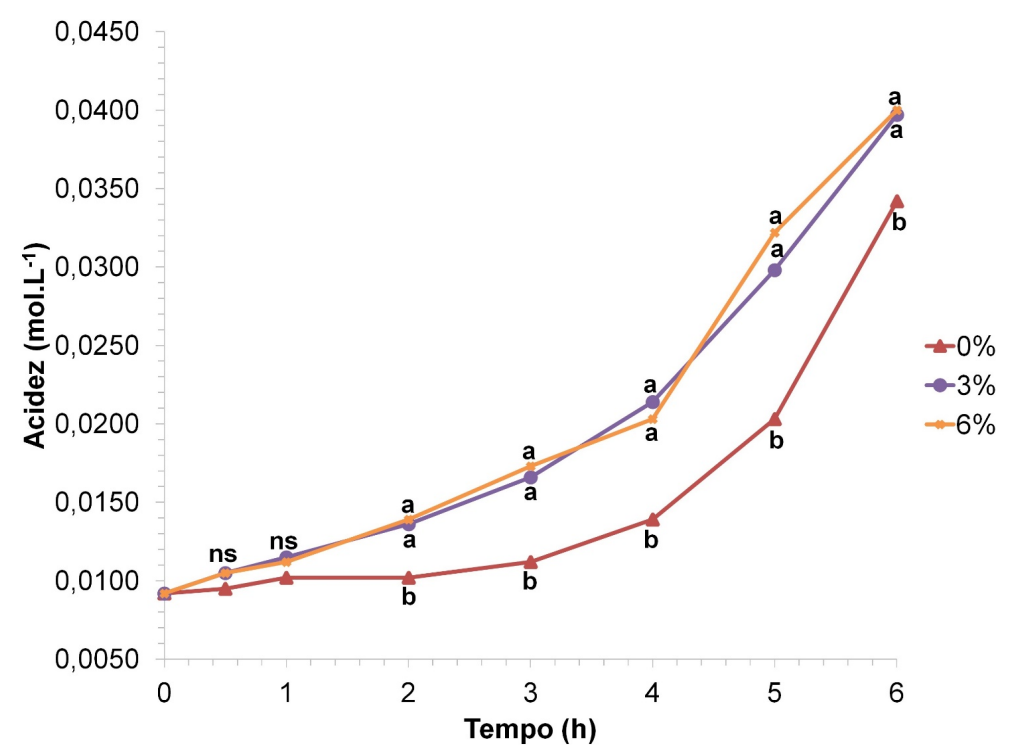

Figura 4. Produção de ácido lático por cultura mista de bactérias láticas (Lactobacillus acidophilus LA-5, Bifidobacterium BB-12 e Streptococcus thermophilus), imobilizadas em esferas de alginato de cálcio, em soro de leite suplementado com extrato de levedura ( $\mathrm{pH}$ inicial 7,0 e temperatura $40^{\circ} \mathrm{C}$ ). ns: Não significativo. Médias seguidas por letras iguais, no mesmo tempo, não diferem significativamente pelo teste de Tukey $(p>0,05)$.

Após duas horas de fermentação, já é possível observar diferença entre o tratamento controle e os tratamentos com $3 \%$ e $6 \%$ de suplementação $(p<0,05)$ de extrato de levedura. A vantagem produtiva de ácido lático persiste ao longo do processo $(p<0,05)$ para o meio suplementado com extrato de levedura ( $3 \%$ e $6 \%$ ), quando comparado com aquele não suplementado $(0 \%)$. Ao final do experimento, não se verificou diferença significativa $(p>0,05)$ entre o tratamento $3 \%$ e $6 \%$, embora esses dois tratamentos tenham se mostrado superiores $(p<0,05)$ ao controle $(0 \%)$, na produção de ácido lático.

Assim como ocorre com a vinhaça, o extrato de levedura é rico em aminoácidos livres, minerais e vitaminas do complexo $\mathrm{B}$, contribuindo para a redução no tempo de adaptação das bactérias láticas (Champagne et al., 2003). Champagne et al. (1999) haviam demonstrado que a suplementação do meio de cultivo por extrato de levedura, em doses crescentes, contribui para a redução no tempo de adaptação da cultura láctea e o aumento na taxa de multiplicação celular.

Uma vez que bactérias láticas têm a produção de ácido lático afetada pelo seu metabolismo de produção de energia (ATP), é esperado que aumentos na taxa de multiplicação celular também sejam acompanhados de aumento na taxa de produção de ácido lático. Isso explica o aumento na taxa de produção de ácido lático já nas horas inicias do processo observado nos tratamentos suplementados com extrato de levedura ( $3 \%$ e $6 \%$ ), quando comparados com o controle ( $0 \%$ ). Dados da literatura corroboram essa hipótese, uma vez que Hauly et al. (2003) observaram que cultura de Lactobacillus curvatus produziram maiores quantidades de ácido lático em meio suplementado com extrato de levedura. $\mathrm{O}$ efeito da suplementação também foi observado por Oliveira et al. (2009) para cultura de Lactobacillus casei cultivada em meio à base de melaço suplementado com $2 \%$ de EL, comparando-se com o meio não suplementado e com aqueles de menores doses de extrato de levedura. Quando o meio foi composto por caldo de cana-de-açúcar, a suplementação com extrato de levedura também foi efetiva no aumento da produção de ácido lático por cultura de Lactobacillus plantarum (Oliveira et al., 2013).

A Figura 5 apresenta a concentração de ácido lático produzido quando utilizado cada um dos três resíduos agroindustriais como suplemento. Todos tratamentos apresentaram aumento na produção de ácido lático em relação ao controle. Entretanto, é possível observar que o extrato de levedura apresentou a maior concentração de ácido lático $(p<0,05), 0,0307 \mathrm{~mol}^{-L^{-1}}$, quando comparado aos demais suplementos. Não foram observadas diferenças significativas entre os tratamentos que utilizaram vinhaça e AMM como fonte de nitrogênio $(p>0,05)$. 


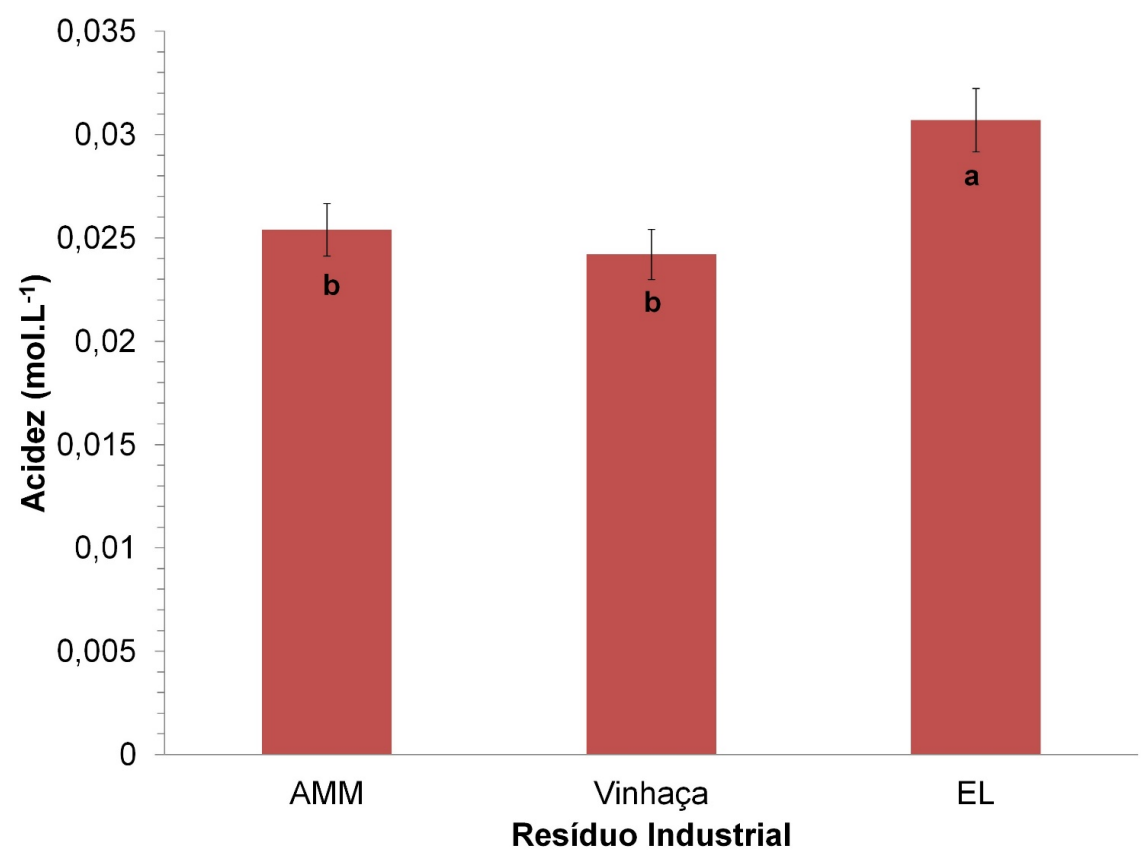

Figura 5. Teor de ácido lático produzido em $6 \mathrm{~h}$ de fermentação de soro de leite suplementado com água de maceração de milho, vinhaça ou extrato de levedura, por cultura mista de bactérias láticas (Lactobacillus acidophilus

LA-5, Bifidobacterium BB-12 e Streptococcus thermophilus), imobilizadas em esferas de alginato de cálcio ( $\mathrm{pH}$ inicial 7,0 e temperatura $40^{\circ} \mathrm{C}$ ). Médias seguidas por letras iguais não diferem significativamente pelo teste de Tukey $(p>0,05)$.

Roy et al. (1986) observaram que Lactobacillus helveticus cultivados em meio à base de soro de queijo produziram mais ácido lático em meio suplementado com extrato de levedura em relação ao meio suplementado com AMM. Isso provavelmente ocorre por ser o extrato de levedura uma excelente fonte de vitaminas do complexo B, sendo frequentemente usado para fornecer esses fatores em meios de cultura bacteriológicos. É também considerado indispensável para obtenção de rápidas taxas de crescimento somado à produção de ácido lático por bactérias láticas (Selmer-Olsen \& Sorhaug, 1998).

\section{Conclusão}

No final da fermentação, ao avaliar o efeito da temperatura e do $\mathrm{pH}$ inicial, observou-se que a temperatura de $40{ }^{\circ} \mathrm{C}$ e o pH inicial de 7,0 apresentaram um teor de ácido lático $10 \%$ superior em relação aos demais tratamentos, indicando que estes valores são os mais indicados para a otimização do processo fermentativo.

Todos os resíduos foram efetivos em aumentar a taxa de produção de ácido lático quando suplementados no soro de leite. Entretanto, não se observou diferença significativa entre os níveis de suplementação para cada resíduo. O extrato de levedura demonstrou melhores resultados com um teor de ácido lático $20 \%$ superior ao da água de maceração de milho e vinhaça.

\section{Referências}

Abdel-Rahman, A. M., Tashiro, Y., \& Sonomoto, K. (2013). Recent advances in lactic acid production by microbial fermentation processes. Biotechnology Advances, 31(6), 877-902. PMid:23624242. http://dx.doi.org/10.1016/j.biotechadv.2013.04.002

Bai, Z., Gao, Z., Sun, J., Wu, B., \& He, B. (2016). D-Lactic acid production by Sporolactobacillus inulinus YBS1-5 with simultaneous utilization of cottonseed meal and corncob residue. Bioresource Technology, 207, 346-352. PMid:26897413. http://dx.doi.org/10.1016/j.biortech.2016.02.007

Bernardo, M. P., Coelho, L. F., Sass, D. C., \& Contiero, J. (2016). L-(+)-Lactic acid production by Lactobacillus rhamnosus B103 from dairy industry waste. Brazilian Journal of Microbiology, 47(3), 640-646. PMid:27266630.

http://dx.doi.org/10.1016/j.bjm.2015.12.001 
Bonk, F., Bastidas-Oyanedel, J.-R., Yousef, A. F., \& Schmidt, J. E. (2017). Exploring the selective lactic acid production from food waste in uncontrolled $\mathrm{pH}$ mixed culture fermentations using different reactor configurations. Bioresource Technology, 238, 416-424. PMid:28458175. http://dx.doi.org/10.1016/j.biortech.2017.04.057

Champagne, C. P., Gaudreau, H., \& Conway, J. (2003). Effect of the production or use of mixtures of bakers' or brewers' yeast extracts on their ability to promote growth of lactobacilli and pediococci. Electronic Journal of Biotechnology, 6(3), 185-197. http://dx.doi.org/10.2225/vol6-issue3-fulltext-3

Champagne, C. P., Gaudreau, H., Conway, J., Chartier, N., \& Fonchy, E. (1999). Evaluation of yeast extracts as growth media supplements for lactococci and lactobacilli by using automated spectrophotometry. The Journal of General and Applied Microbiology, 45(1), 17-21. PMid:12501397. http://dx.doi.org/10.2323/jgam.45.17

Ding, S., \& Tan, T. (2006). L-lactic acid production by Lactobacillus casei fermentation using different fed-batch strategies. Process Biochemistry, 41(6), 1451-1454. http://dx.doi.org/10.1016/j.procbio.2006.01.014

Dowd, M. K., Johansen, S. L., Cantarella, L., \& Reilly, P. J. (1994). Low molecular weight organic composition of ethanol stillage from sugarcane molasses, citrus waste, and sweet whey. Journal of Agricultural and Food Chemistry, 42(2), 283-288. http://dx.doi.org/10.1021/jf00038a011

Hauly, M. C. O., Oliveira, A. R., \& Oliveira, A. S. (2003). Produção de ácido lático por Lactobacillus curvatus em melaço de cana-de-açúcar. Semina: Ciências Agrárias, 24(1), 133-142. http://dx.doi.org/10.5433/1679-0359.2003v24n1p133

Hofvendahl, K., \& Hahn-Hagerdal, B. (1997). L-lactic acid production from whole wheat flour hydrolysate using strains of Lactobacilli and Lactococci. Enzyme and Microbial Technology, 20(4), 301-307. http://dx.doi.org/10.1016/S01410229(97)83489-8

Hofvendahl, K., \& Hahn-Hagerdal, B. (2000). Factors affecting the fermentative lactic acid production from renewable resources. Enzyme and Microbial Technology, 26(2-4), 87-107. PMid:10689064. http://dx.doi.org/10.1016/S0141-0229(99)00155-6

Lima, C. J. B., Coelho, L. F., Blanco, K. C., \& Contiero, J. (2009). Response surface optimization of D (-)-lactic acid production by Lactobacillus SMI8 using corn steep liquor and yeast autolysate as an alternative nitrogen source. African Journal of Biotechnology, 8(21), 5842-5846. http://dx.doi.org/10.5897/AJB09.627

Lopes-Filho, J. F., Ramos, A. P., \& Romero, J. T. (2006). Water, sulfur dioxide and lactic acid difusivities in corn grains during steeping for wet milling. Brazilian Journal of Food Technology, 9(4), 257-263.

Martinez, F. A. C., Balciunas, E. M., Salgado, J. M., González, J. M. D., Conveti, A., \& Oliveira, R. P. S. (2013). Lactic acid properties, applications and production: a review. Trends in Food Science \& Technology, 30(1), 70-83. http://dx.doi.org/10.1016/j.tifs.2012.11.007

Mirdamadi, S., Atashgahi, S., Rajabi, A., Aziz-Mohseni, F., Roayaei, M., \& Hamedi, J. (2008). Cell entrapment of Lactobacillus casei subsp. casei ATCC 39392 for latic acid production. Iranian Journal of Biotechnology, 6(1), 16-21.

Mozzi, F., Raya, R. R., \& Vignolo, G. M. (2015). Biotechnology of lactic acid bacteria: novel applicattions (392 p). lowa: WileyBlackwell. http://dx.doi.org/10.1002/9781118868386.

Oliveira, D. F. D., Tonial, I. B., \& Bravo, C. E. C. (2013). Produção de ácido lático e viabilidade celular de Lactobacillus plantarum inoculado em caldo de cana-de-açúcar (Saccharum spp.) suplementado. Revista Pan-Amazônica de Saúde, 4(4), 67-71. http://dx.doi.org/10.5123/S2176-62232013000400008

Oliveira, R. F., Sousdaleff, M., Lima, M. V. S., \& Lima, H. O. S. (2009). Produção fermentativa de ácido lático a partir do melaço da cana-de-açúcar por Lactobacillus casei. Brazilian Journal of Food Technology, 2, 1-7. Edição Especial.

Panesar, P. S., Kennedy, J. F., Gandhi, D. N., \& Bunko, K. (2007). Bioutilisation of whey for lactic acid production. Food Chemistry, 105(1), 1-14. http://dx.doi.org/10.1016/j.foodchem.2007.03.035

R Core Team. (2016). R: a language and environment for statistical computing. Vienna: R Foundation for Statistical Computing. Recuperado em 7 de maio de 2018, de http://www.R-project.org/

Roy, D., Goulet, J., \& Leduy, A. (1986). Batch fermentation of whey ultrafiltrate by Lactobacillus he/veticus for lactic acid production. Applied Microbiology and Biotechnology, 24(3), 206-213. http://dx.doi.org/10.1007/BF00261538

Selmer-Olsen, E., \& Sorhaug, T. (1998). Comparative studies of the growth in whey supplemented with autolysate from brewery yeast biomass or commercial yeast of Lactobacillus plantarum extract. Milchwissenschaft. Milk Science International, 53(7), 367-370.

Silva, J. L., Beluomini, M. A., Sedonho, G. C., \& Stradiotto, N. R. (2017). Determination of amino acids in sugarcane vinasse by ion chromatographic using nickel nanoparticles on reduced graphene oxide modified electrode. Microchemical Journal, 134, 374-382. http://dx.doi.org/10.1016/j.microc.2017.07.007

Soska, J. (1966). Growth of Lactobacillus acidophilus in the absence of folic acid. Journal of Bacteriology, 91(5), 1840-1847. PMid:4957024.

Tosungnoen, S., Chookietwattana, K., \& Dararat, S. (2014). Lactic acid production from repeated-batch and simultaneous saccharification and fermentation of cassava starch wastewater by amylolytic Lactobacillus plantarum MSUL 702. APCBEE Procedia, 8, 204-209. http://dx.doi.org/10.1016/j.apcbee.2014.03.028

Vijayakumar, J., Aravindan, R., \& Viruthagiri, T. (2008). Recent trends in the production, purification and application of lactic acid. Chemical and Biochemical Engineering Quarterly, 22(2), 245-264.

Wee, Y. J., Kim, J. N., \& Ryu, H. W. (2006). Biotechnological production of lactic acid and its recent applications. Food Technology and Biotechnology, 44(2), 163-172. 
Zali, A., Eftekhari, M., Fatehi, F., \& Ganjkhanlou, M. (2017). Effect of vinasse (condensed molasses solubles) on performance and meat chemical composition of Holstein male calves. Italian Journal of Animal Science, 16(3), 515-520. http://dx.doi.org/10.1080/1828051X.2017.1298407

Zenebon, O., Pascuet, N. S., \& Tiglea, P. (2008). Métodos físico-químicos para análise de alimentos (1020 p.). São Paulo: Instituto Adolfo Lutz.

Zheng, J., Gao, M., Wang, Q., Wang, J., Sun, X., Chang, Q., \& Tashiro, Y. (2017). Enhancement of L-latic acid production via synergism in open co-fermentation of Sophora flavescens residues and food waste. Bioresource Technology, 225, $159-164$. PMid:27888733. http://dx.doi.org/10.1016/j.biortech.2016.11.055 